\title{
List of Reviewers
}

The list below contains the reviewers for Vol 1, Issue 2, 2018 :

Anggraeni Permatasari, School of Business Management, ITB, Bandung, Indonesia Dedi Rianto Rahadi, President University, Indonesia

Dr. Ajay Chauhan, President University, Indonesia

Dr. Hajanirina Adriananteina, President University, Indonesia

Dr. Ika Pratiwi, President University, Indonesia

Dr. Muana Nanga, President University, Indonesia

Dr. Mohar Yusof, Universiti Tun Abdul Razak, Malaysia

Grisna Anggadwita, Telkom University, Indonesia

Jhanghiz Syahrivar, Corvinus University of Budapest, Hungary

Suresh Kumar, President University, Indonesia

Editors and staff of IJFBP express their gratitude to the reviewers of this issue. 